\title{
The role of sediment-induced light attenuation on primary production during Hurricane Gustav (2008)
}

\author{
Zhengchen Zang ${ }^{1, a}$, Z. George Xue ${ }^{1,2,3}$, Kehui Xu ${ }^{1,3}$, Samuel J. Bentley ${ }^{3,4}$, Qin Chen ${ }^{5}$, Eurico J. D'Sa ${ }^{1,3}$, Le Zhang ${ }^{1}$, \\ and Yanda $\mathrm{Ou}^{1}$ \\ ${ }^{1}$ Department of Oceanography and Coastal Sciences, Louisiana State University, 70803 Baton Rouge, LA, USA \\ ${ }^{2}$ Center for Computation and Technology, Louisiana State University, 70803 Baton Rouge, LA, USA \\ ${ }^{3}$ Coastal Studies Institute, Louisiana State University, 70803 Baton Rouge, LA, USA \\ ${ }^{4}$ Department of Geology and Geophysics, Louisiana State University, 70803 Baton Rouge, LA, USA \\ ${ }^{5}$ Department of Civil and Environmental Engineering, Northeastern University, 02115 Boston, MA, USA \\ ${ }^{a}$ now at: Department of Biology, Woods Hole Oceanographic Institution, 02543 Woods Hole, MA, USA
}

Correspondence: Z. George Xue (zxue@lsu.edu)

Received: 17 February 2020 - Discussion started: 25 March 2020

Revised: 26 July 2020 - Accepted: 24 August 2020 - Published: 20 October 2020

\begin{abstract}
We introduced a sediment-induced light attenuation algorithm into a biogeochemical model of the Coupled Ocean-Atmosphere-Wave-Sediment Transport (COAWST) modeling system. A fully coupled ocean-atmosphericsediment-biogeochemical simulation was carried out to assess the impact of sediment-induced light attenuation on primary production in the northern Gulf of Mexico during the passage of Hurricane Gustav in 2008. When compared with model results without sediment-induced light attenuation, our new model showed a better agreement with satellite data on both the magnitude of nearshore chlorophyll concentration and the spatial distribution of offshore bloom. When Hurricane Gustav approached, resuspended sediment shifted the inner shelf ecosystem from a nutrientlimited one to a light-limited one. Only 1 week after Hurricane Gustav's landfall, accumulated nutrients and a favorable optical environment induced a posthurricane algal bloom in the top $20 \mathrm{~m}$ of the water column, while the productivity in the lower water column was still light-limited due to slow-settling sediment. Corresponding with the elevated offshore $\mathrm{NO}_{3}$ flux $\left(38.71 \mathrm{mmol} \mathrm{N} \mathrm{m}^{-1} \mathrm{~s}^{-1}\right.$ ) and decreased chlorophyll flux (43.10 $\left.\mathrm{mg} \mathrm{m}^{-1} \mathrm{~s}^{-1}\right)$, the outer shelf posthurricane bloom should have resulted from the crossshelf nutrient supply instead of the lateral dispersed chlorophyll. Sensitivity tests indicated that sediment light attenuation efficiency affected primary production when sediment concentration was moderately high. Model uncertainties due
\end{abstract}

to colored dissolved organic matter and parameterization of sediment-induced light attenuation are also discussed.

\section{Introduction}

Light, nutrients and temperature play a vital role in photosynthesis and marine ecosystems. The vertical structure of light availability in an aquatic environment is mainly modulated by the shading effects of chlorophyll, colored dissolved organic matter (CDOM), detritus and sediment (Cloern, 1987; Devlin et al., 2008; Ganju et al., 2014; McSweeney et al., 2017; Schaeffer et al., 2011). The optical environment in river-dominated shelves are more complex due to the interaction between riverine inputs and regional hydrodynamics (Bierman et al., 1994; Lin et al., 2009; Zhu et al., 2009). As the largest river in North America, the MississippiAtchafalaya river system delivers $380 \mathrm{~km}^{3}$ of freshwater and $115 \mathrm{Mt}$ of sediments each year into the northern Gulf of Mexico (nGoM; Meade and Moody, 2010; Allison et al., 2012). Along the Louisiana-Texas shelf in the nGoM, suspended sediment concentration (SSC) in the water column exhibits strong seasonality, i.e., high in the winter and spring seasons due to strong sediment resuspension and high fluvial sediment discharge, while largely reduced in summer and fall owing to the relatively low river inputs and weak resuspension (Zang et al., 2019). Episodic hurricane events in summer 
and fall can disturb vertical stratification and resuspend large amount of shelf sediment (D'Sa et al., 2011; Xu et al., 2016; Zang et al., 2018). Enhanced resuspension during a hurricane might greatly change the shelf ecosystem via modifying light availability. In addition, enhanced organic matter remineralization in the bottom boundary layer could also introduce sharp changes to the ecosystem (Hurst et al., 2019; Wilson et al., 2013). Yet studies of the impact from hurricaneinduced resuspension are still limited due to the challenge of in situ data collection under extreme weather conditions.

As an alternative tool to fill in the spatial and temporal gaps in the in situ data sets, coupled physicalbiogeochemical models have been widely applied to the Gulf of Mexico (GoM; e.g., Fennel et al., 2008; Laurent et al., 2012; Xue et al., 2013; Yu et al., 2015; Gomez et al., 2018). In these models, photosynthetically available radiation was estimated using a similar method, namely light availability decreasing exponentially with water depth and the concentrations of light absorbers (e.g., sediment and CDOM) in the overlying water column. Due to the lack of long-term observations of CDOM, however, its impact on the optical environment was either not included (e.g., Fennel et al., 2006; Gomez et al., 2018) or simply expressed as a function of salinity (Justić and Wang, 2014). Although most of these studies considered sediment-induced light attenuation when estimating primary production, the related parameterization was uniform over the entire research domain and did not vary with sediment dynamics (e.g., Zhou et al., 2017; Thewes et al., 2020). Such an oversimplified treatment of sediment-induced light attenuation could substantially impact a model's robustness in river-dominated shelves that encompass a wide range of SSC. In the nGoM, Justić and Wang (2014) tentatively employed a new scheme by connecting sediment-induced light attenuation with river discharge (salinity) and hydrodynamics (bottom shear stress). However, the horizontal distribution of SSC in a realistic environment is not necessarily correlated with that of the freshwater plume, and the contribution of resuspension to SSC at different depths might be significantly different (Xu et al., 2011, 2016).

Hurricane Gustav (hereafter, Gustav) was the first major hurricane that made a landfall in Louisiana after Hurricane Katrina (2005). It passed through the center of GoM and landed near Cocodrie, Louisiana, on 1 September 2008 as a category 2 hurricane (Forbes et al., 2010). Sediment resuspension and transport were strong during the passage of Gustav, and thick posthurricane deposition (up to $40 \mathrm{~cm}$ ) was simulated on the inner shelf (Zang et al., 2018) and in the bays (Liu et al., 2018). Korobkin et al. (2009) identified a post-Gustav algal bloom around the Mississippi delta on satellite images. High respiration and stratification after the landfall of Gustav was reported to be connected with possible hypoxia development on the shelf (McCarthy et al., 2013).

In this study, we introduce a new biogeochemical model, with sediment-induced light attenuation, to the three- way coupled (atmospheric-wave-ocean-sediment transport) Gustav model (Zang et al., 2018). While sediment dynamics can also impact nutrient dynamics via changing the intensity of remineralization near the bottom (Moriarty et al., 2018), the scope of this study is to investigate the influence of suspended sediment on the optical environment and, thus, primary production. The impact from elevated remineralization of resuspended particular organic matter during hurricane events is not considered as being detailed processes because relevant parameterizations are still largely unknown. The objectives of this paper are to (1) evaluate the impact of sediment-induced light attenuation on the spatiotemporal variation in nutrient-phytoplankton dynamics during a hurricane event, (2) explore the driving mechanism of the posthurricane bloom on the shelf and (3) investigate the response of primary production to sediment optical characteristics.

\section{Model description}

\subsection{Physical, sediment and biogeochemical models}

Our model covered the entire GoM (Fig. 1a) and was built on the Coupled Ocean-Atmosphere-Wave-Sediment Transport (COAWST) modeling system (Warner et al., 2008, 2010). COAWST is an open-source model platform that consists of three numerical models, namely the Weather Research and Forecasting (WRF) model (Skamarock et al., 2008), the Regional Ocean Modeling System (ROMS; Shchepetkin and McWilliams, 2005; Haidvogel et al., 2008) and the Simulating WAves Nearshore (SWAN) model (Booij et al., 1999). The Community Sediment Transport Modeling System (CSTMS) is included in ROMS to simulate sediment transport, stratigraphy and geomorphology. The model coupling toolkit (MCT; Jacob et al., 2005) enables the interaction among these three models. The details of the model setup and validation of the three-way coupled hydrodynamicsediment transport model (WRF-ROMS-SWAN-CSTMS) were described in Zang et al. (2018), where four types of sediment (two cohesive and two noncohesive) were defined with different grain diameters and settling velocities. There were 40 sediment layers on the sea floor with a total thickness of $1 \mathrm{~m}$ to resolve sediment bed erosion and deposition. The driving force of sediment resuspension was determined by bottom shear stress induced by wave and current. Readers are referred to Zang et al. (2018) for a detailed hydrodynamic and sediment validation.

Given the importance of diatom in the phytoplankton community in the nGoM (Zhao and Quigg, 2014), it is necessary to have both nitrogen and silicon cycles in the model. The biogeochemical model in this study was largely built on the North Pacific Ecosystem Model for Understanding Regional Oceanography (NEMURO; Kishi et al., 2007), which incorporated both nitrogen and silicon flows. There were 11 state variables included in the model, namely nitrate, am- 
(a) Model domains (WRF + ROMS + SWAN) Depth (m)

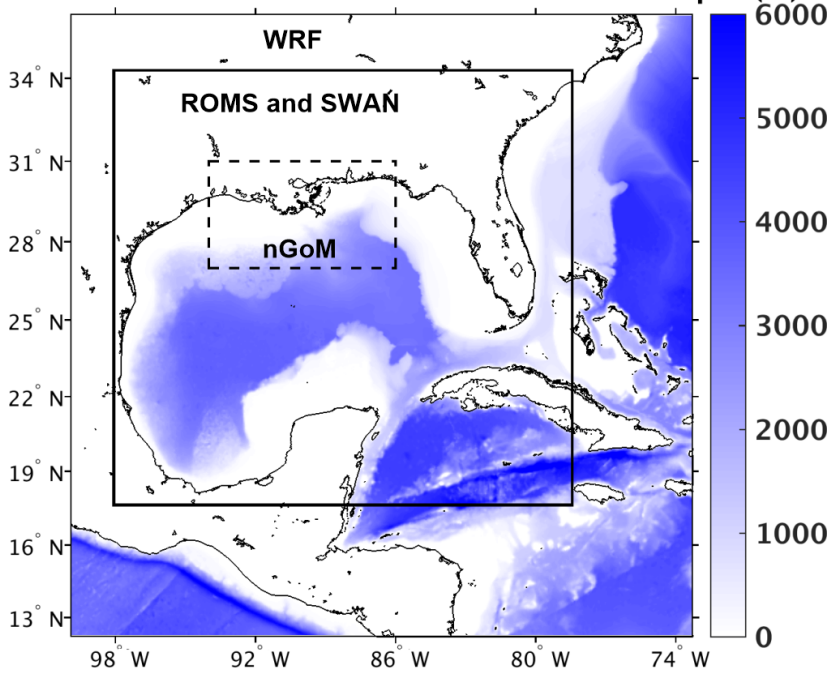

(b) Northern Gulf of Mexico (nGoM)

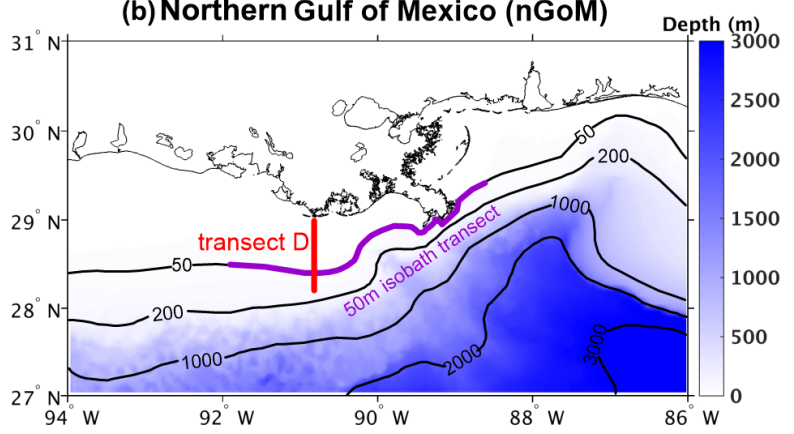

Figure 1. Model domains applied in this study. The entire panel (a) is the WRF model domain (6 km resolution) overlaid with water depth (colored shading). The black box represents the model grid used by ROMS and SWAN, with a $5 \mathrm{~km}$ resolution. The black box with a dashed line $\left(27-31^{\circ} \mathrm{N}, 94-86^{\circ} \mathrm{W}\right)$ covers the northern Gulf of Mexico (nGoM). More details on the nGoM are shown in (b). The thick purple and red lines indicate the locations of $50 \mathrm{~m}$ isobath transect and transect D (Rabalais et al., 2001), respectively.

monium, two types of phytoplankton (small and large), three types of zooplankton (microzooplankton, mesozooplankton and predatory zooplankton), particulate and dissolved nitrogen, particulate silica, and silicic acid concentration. River nutrient discharge during the hurricane was retrieved from the United States Geological Survey (USGS) Water Data for the Nation website (http://nwis.waterdata.usgs.gov; station no. 07374000 ). The growth of phytoplankton was driven by water temperature, light availability and nutrient concentration. Instantaneous remineralization of particulate organic nitrogen at the bottom was estimated following Fennel et al. (2006). Our model did not include phosphate because its limitation on primary production in the $\mathrm{nGoM}$ was mainly between May and July (Laurent et al., 2012; Laurent and Fennel, 2014). We incorporated two types of chlorophyll corresponding to the large and small phytoplankton tracers, respectively. Following Fennel et al. (2006), chlorophyll dynamics was derived from a phytoplankton equation by multiplying the ratio of chlorophyll to phytoplankton biomass. To obtain an ideal parameterization set and a stable initial condition for the biogeochemical variables, we first conducted a $20 \mathrm{yr}$ (1993-2012) coupled physicalbiogeochemical simulation using only the ROMS model, where WRF and SWAN were disabled to achieve a feasible computation load (step 1 in Fig. 2). The atmospheric forcing was provided by the $6 \mathrm{~h}, 38 \mathrm{~km}$ horizontal resolution Climate Forecast System Reanalysis (CFSR; Saha et al., 2010, 2011; http://cfs.ncep.noaa.gov). The physical setup of the 20 year simulation was the same as Zang et al. (2019). The biogeochemical parameterizations (Table S1 in the Supplement) were largely adapted after a recent GoM biogeochemical modeling study by Gomez et al. (2018). Since this study focused on the response of the biogeochemical process to hurricane events, details of the 20 year simulation setup and model observation comparison were provided in the Supplement. Once validated, the biogeochemical variables were extracted from the 20 year model on 30 August 2008 as the initial condition for this Gustav simulation (Step 2 in Fig. 2).

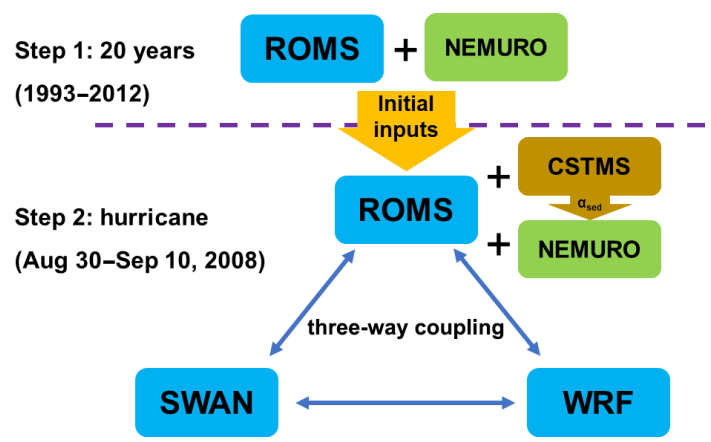

Figure 2. Flow chart of long-term (20 years) and hurricane $(11 \mathrm{~d})$ simulations. In step 1 we only run ocean (ROMS) and biogeochemical (NEMURO) models, which provide initial inputs for the next step. Step 2 couples ocean (ROMS), wave (SWAN), atmosphere (WRF), sediment (CSTMS) and new biogeochemical (NEMURO) models with the new sediment-induced light attenuation term.

The light available for photosynthesis $(I)$ is estimated using the following equation (McSweeney et al., 2017):

$$
\begin{aligned}
& I=I_{0} \cdot \operatorname{par} \cdot \exp \left\{-Z\left[\alpha_{\mathrm{w}}+\alpha_{\mathrm{chl}} \int_{z}^{0}(\mathrm{PSn}+\mathrm{PLn}) \mathrm{d} z\right.\right. \\
& \left.\left.+\alpha_{\mathrm{sed}} \int_{z}^{0} \mathrm{SSCd} z\right]\right\},
\end{aligned}
$$

where $I_{0}$ is the light intensity at the surface layer, and $Z$ is the water depth. par is the fraction of light available for photosynthesis (specified as 0.43). $\alpha_{\mathrm{w}}$ and $\alpha_{\mathrm{chl}}$ are the light attenuation coefficients of sea water and chlorophyll, respec- 
tively. PSn and PLn represent concentrations of small and large phytoplankton. Compared with the original biogeochemical model, we added a new sediment-induced light attenuation term in this equation. $\alpha_{\text {sed }}$ is the light attenuation coefficient due to suspended sediment, and SSC is total suspended sediment concentration in the respective layer. We performed a benchmark run $\left(\alpha_{\text {sed }}=0.059\right.$; McSweeney et al., 2017) to represent the scenarios with sediment-induced light attenuation. The simulation period was from 30 August to 10 September 2008.

\subsection{Sensitivity tests}

High turbidity in the Mississippi River delta due to fluvial sediment discharge and resuspension suggested the vital role of sediment in the underwater optical environment. To quantitatively evaluate the importance of suspended sediment in light attenuation, we conducted a sensitivity test (test 1 ) without sediment-induced light attenuation $\left(\alpha_{\text {sed }}=0\right)$. Since the physical properties of a sediment particle (e.g., size, shape, roughness and color) determine its light attenuation efficiency (Baker and Lavelle, 1984; Storlazzi et al., 2015), a wide range of $\alpha_{\text {sed }}(0.025-0.075)$ has been reported in previous studies (e.g., Pennock, 1985; Van Duin et al., 2001; Arndt et al., 2007; McSweeney et al., 2017). Here, we increased or decreased the benchmark $\alpha_{\text {sed }}(0.059)$ by $20 \%$ and $40 \%$ to examine the sensitivity of primary production to sedimentinduced light attenuation (tests 2-5). The rest of the model setup was the same between the benchmark run and sensitivity tests (tests $1-5$ ). The deviation due to the chaotic nature of turbulence was not considered in this study.

\section{Model validation}

Direct measurements of ocean conditions during the passage of a hurricane are still challenging. In Zang et al. (2018) we validated the physical model's performance against the air pressure, sea level and wave heights recorded at available buoy stations. The sediment model's performance was evaluated against satellite images. In this study, we used the $5 \mathrm{~d}$ composites of SeaWiFS chlorophyll data (OC4) obtained before (25-29 August) and after (5-9 September) Gustav's landing to calibrate our biogeochemical model's initial condition and results. Surface chlorophyll distribution during initial condition (Fig. 3a) was similar to that in the prehurricane composite imagery (Fig. 3b), with a high chlorophyll concentration $\left(>4 \mathrm{mg} \mathrm{m}^{-3}\right)$ located around the birdfoot delta and the Atchafalaya inner shelf and values declined seaward to $\sim 0.1 \mathrm{mg} \mathrm{m}^{-3}$.

Compared with the prehurricane composite imagery, the posthurricane composite showed a higher chlorophyll concentration around the bird-foot delta and on the Atchafalaya shelf (Fig. 3b and c). Another major increase was identified in waters between the 50 and $200 \mathrm{~m}$ isobaths off the
Atchafalaya Bay with the chlorophyll concentration increasing from 1 to $4 \mathrm{mg} \mathrm{m}^{-3}$ after Gustav, indicating a possible posthurricane algal bloom on the outer shelf. When comparing with the model run without sediment-induced attenuation, the intensity of the offshore bloom was better reproduced $\left(\sim 4 \mathrm{mg} \mathrm{m}^{-3}\right)$ with the new sediment-induced light attenuation algorithm (see the difference between Fig. 3d and e). To quantitatively evaluate the model's performance, we calculated the root mean square error (RMSE) and correlation coefficient $(R)$ between model-simulated and satellitederived chlorophyll concentrations over the inner shelf (water depth $<50 \mathrm{~m}$; Fig. 4). The reduced RMSE in the benchmark run in comparison to sensitivity test (2.33 to 1.91 ) suggested improved model performance with sediment-induced light attenuation. However, with only marginal differences in the correlation coefficients between the two experiments (0.82 and 0.81 ), the spatial distributions of chlorophyll were comparable (Fig. 4). Nevertheless, the model's performance in the high-productivity waters (both simulated and observed chlorophyll concentrations $>1 \mathrm{mg} \mathrm{m}^{-3}$ ) was significantly improved ( $R$ increased from 0.55 to 0.61 and RMSE decreased from 5.93 to 3.97 ; Fig. 4). The improvement in model results confirmed the importance of sediment-induced light attenuation in biogeochemical cycling during a hurricane event, particularly in coastal regions where chlorophyll concentration was high.

\section{Results and discussion}

\subsection{Temporal variability of biogeochemical variables}

To examine the temporal variation in biogeochemical variables during the passage of Gustav, we plotted the time series of spatially averaged net primary production (NPP; growth of phytoplankton minus the respiratory losses), surface chlorophyll concentration, surface $\mathrm{NO}_{3}$ concentration, $\mathrm{SSC}$, downward solar shortwave radiation and sea surface temperature (SST) over the nGoM inner shelf (Fig. 5; $<50 \mathrm{~m}$ water depth). NPP exhibited strong diel variation, and the peaks were strongly correlated with shortwave radiation maximum (Fig. 5a and e). Such a diel cycle could also be found in chlorophyll concentration but with a 3 to $4 \mathrm{~h}$ delay (Fig. 5b). Before the arrival of Gustav, daily averaged NPP was around $0.05 \mathrm{~g} \mathrm{C} \mathrm{m}^{-2} \mathrm{~h}^{-1}$, and the differences in NPP and chlorophyll concentration between the benchmark run and test 1 were minor (Fig. 5a and b).

Following Gustav's landfall along coastal Louisiana at 16:00 Coordinated Universal Time (UTC) on 1 September, surface SSC increased to $3.8 \mathrm{~kg} \mathrm{~m}^{-3}$ because of strong seabed resuspension (Fig. 5d). Daily averaged NPP reduced to $0.03 \mathrm{~g} \mathrm{C}\left(\mathrm{m}^{2} \mathrm{~h}^{-1}\right)^{-1}$ in test 1 . Once sediment-induced light attenuation was included, daily averaged NPP further declined to $0.01 \mathrm{~g} \mathrm{C}\left(\mathrm{m}^{2} \mathrm{~h}^{-1}\right)^{-1}$, suggesting that light availability severely limited short-term productivity on the in- 

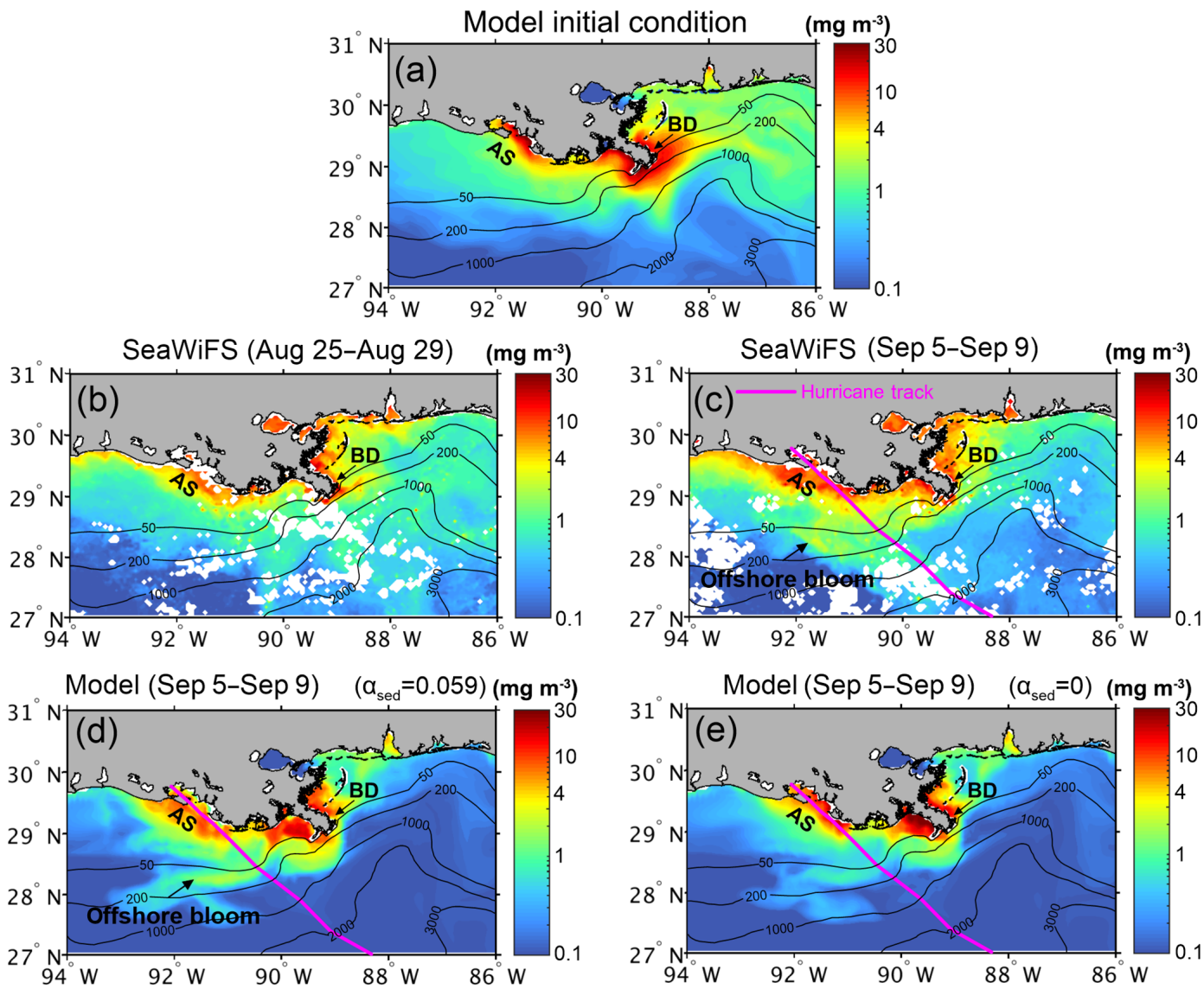

Figure 3. Initial condition of surface chlorophyll extracted from a 20 year simulation (a) and $5 \mathrm{~d}$ composite of surface chlorophyll concentration in the year 2008. (b) SeaWiFS data before Hurricane Gustav (25-29 August). (c) SeaWiFS data after Gustav (5-9 September). (d) Benchmark run result $\left(\alpha_{\text {sed }}=0.059\right)$ after Gustav. (e) Test 1 result $\left(\alpha_{\text {sed }}=0\right)$ after Gustav. White coloring in (b) and (c) represents no data. The magenta curve shows the hurricane track in (b-d). Note: BD - bird-foot Mississippi delta; AS - Atchafalaya shelf.

ner shelf. Chlorophyll concentrations in the benchmark run and test 1 were reduced by $40 \%$ as Gustav approached. Hurricane-related surface cooling, together with decreased light (Fig. 5e and f), contributed to the reductions in both chlorophyll and NPP.

The difference in daily averaged NPP between the benchmark run and test 1 maximized on 2 September due to light limitation modulated by resuspended sediment (Fig. 5a and d). On 3 September, daily averaged NPP of test 1 re-

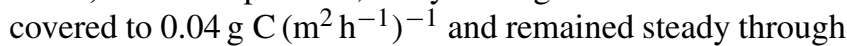
the end of our simulation (Fig. 5a). For the benchmark run, however, the recovery of NPP was much slower; daily averaged NPP was lower than that of test 1 until 7 September when most of the suspended sediment settled back onto the seabed. The $\mathrm{NO}_{3}$ concentration went up gradually between 2 and 7 September in the benchmark run (Fig. 5c) as the nutrient consumption was constrained by the decline in photosynthetic activity. Accumulated $\mathrm{NO}_{3}$, together with the improved optical environment due to low SSC, resulted in higher NPP and algal bloom after 7 September (Fig. 5a and $b$ ).
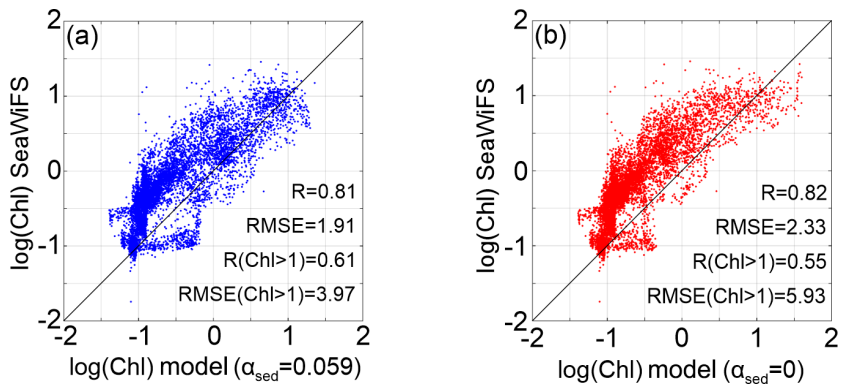

Figure 4. Simulated $5 \mathrm{~d}$ composite (5-9 September) of surface chlorophyll concentration after Gustav compared to the corresponding SeaWiFS-derived surface chlorophyll results over the nGoM inner shelf $(h<50 \mathrm{~m})$ for model results based on (a) benchmark $\left(\alpha_{\text {sed }}=0.059\right)$ and $(\mathbf{b})$ test $1\left(\alpha_{\text {sed }}=0\right)$ runs.

\subsection{Vertical structure of biogeochemical variables}

We extracted concentrations of chlorophyll, $\mathrm{NO}_{3}$, sediment and water density anomaly along transect $\mathrm{D}$ in Rabalais et al. (2001; see Fig. 1b for transect D location) at three 

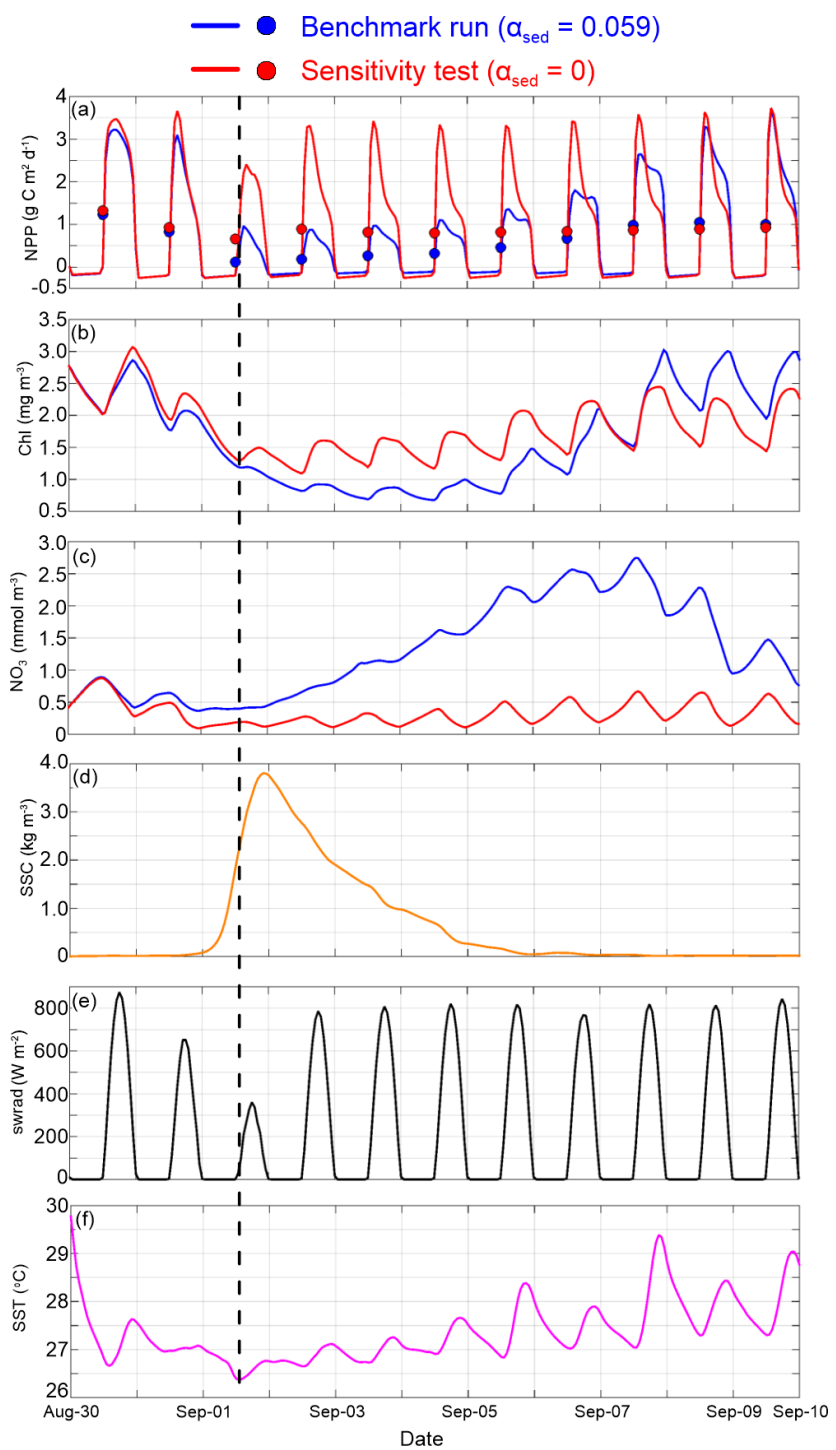

Figure 5. Time series of spatially averaged (inner shelf; water depth $<50 \mathrm{~m}$ ) net primary production (a), surface chlorophyll concentration (b), surface $\mathrm{NO}_{3}$ concentration (c), surface suspended sediment concentration (d), solar shortwave radiation (e) and sea surface temperature (f). In (a-c), blue represents the benchmark run $\left(\alpha_{\text {sed }}=0.059\right)$ and red represents test $1\left(\alpha_{\text {sed }}=0\right)$. Dots in (a) are the daily averaged net primary production. The black dashed line shows the time of the Gustav landfall.

time points (31 August, 2 September and 10 September) to represent pre-, during and posthurricane stages, respectively (Figs. 6 and 7). Before the approach of Gustav, offshore water was well stratified (Fig. 7d). Chlorophyll concentration decreased seaward from 5 to $0.3 \mathrm{mg} \mathrm{m}^{-3}$ (Fig. 6a and d). Sediment-induced light attenuation did not alter the vertical structure of the chlorophyll and $\mathrm{NO}_{3}$ much (Fig. 6a, d, $\mathrm{g}$ and $\mathrm{j}$ ) owing to low SSC in the water column (Fig. 7a). On 2 September, strong vertical mixing increased the SSC to more than $1 \mathrm{~kg} \mathrm{~m}^{-3}$ over the entire water column (Fig. 7b and e). Chlorophyll concentration in waters $<40 \mathrm{~m}$ in the benchmark run was $\sim 4 \mathrm{mg} \mathrm{m}^{-3}$, lower than that in test 1 due to sediment-induced light attenuation (Fig. $6 \mathrm{~b}$ and e). Higher $\mathrm{NO}_{3}$ concentration in the benchmark run was a result of the weakened primary production and nutrient consumption (Fig. $6 \mathrm{~h}$ and $\mathrm{k}$ ). The most striking differences in chlorophyll and $\mathrm{NO}_{3}$ between the two simulations were in water shallower than $20 \mathrm{~m}$.

In test 1, chlorophyll concentration during the posthurricane stage was lower than that of the prehurricane stage (Fig. 6a and c), in contrast to the condition captured by satellite imagery (Fig. $3 \mathrm{~b}$ and c). The benchmark run, however, successfully reproduced the magnitude and seaward extension of the posthurricane bloom (Fig. 6f). High chlorophyll concentration (>1 $\mathrm{mg} \mathrm{m}^{-3}$; Fig. 6f) with low $\mathrm{NO}_{3}$ (Fig. 6l) was simulated in the top $20 \mathrm{~m}$ of the water column where stratification partially recovered (Fig. 7f) and sediment concentration was low after the passage of Gustav (Fig. 7c). At water deeper than $20 \mathrm{~m}$, the chlorophyll concentration dropped drastically to less than $0.1 \mathrm{mg} \mathrm{m}^{-3}$, while the $\mathrm{NO}_{3}$ concentration further increased to $>1 \mathrm{mmol} \mathrm{m}^{-3}$. The synchronized high turbidity and low chlorophyll concentration implied that, $9 \mathrm{~d}$ after Gustav's landfall, the primary production in deeper water could still be constrained by light availability. A similar vertical structure (high SSC and low chlorophyll at the bottom) was also simulated in the Delaware estuary, where near-bottom productivity was constrained by the estuarine turbidity maximum (McSweeney et al., 2017). Such a stratified water column with high and/or low productivity at the surface and/or bottom is generally favorable for bottom oxygen depletion. The elevated surface phytoplankton growth following the hurricane could thus result in increased particulate organic matter (POM) whose remineralization contributes to bottom water hypoxia (Wiseman et al., 1997). Meanwhile, the posthurricane stratification recovery in the summer and fall seasons would have likely prevented oxygen ventilation to the bottom. The high respiration rate caused by resuspended POM could further lower the oxygen level (Bianucci et al., 2018). McCarthy et al. (2013) reported a post-Gustav respiration peak associated with organic matter resuspension in the bottom boundary layer. A recent numerical model study also simulated a substantial increase in near-bottom oxygen consumption due to resuspended POM remineralization during moderate resuspension events (Moriarty et al., 2018). These past studies and the new finding of this study suggest that particulate matter (both organic and inorganic) dynamics might substantially contribute to bottom oxygen depletion and hypoxia development following a hurricane passage. More in situ observations of oxygen dynamics in the bottom boundary layer are needed. 

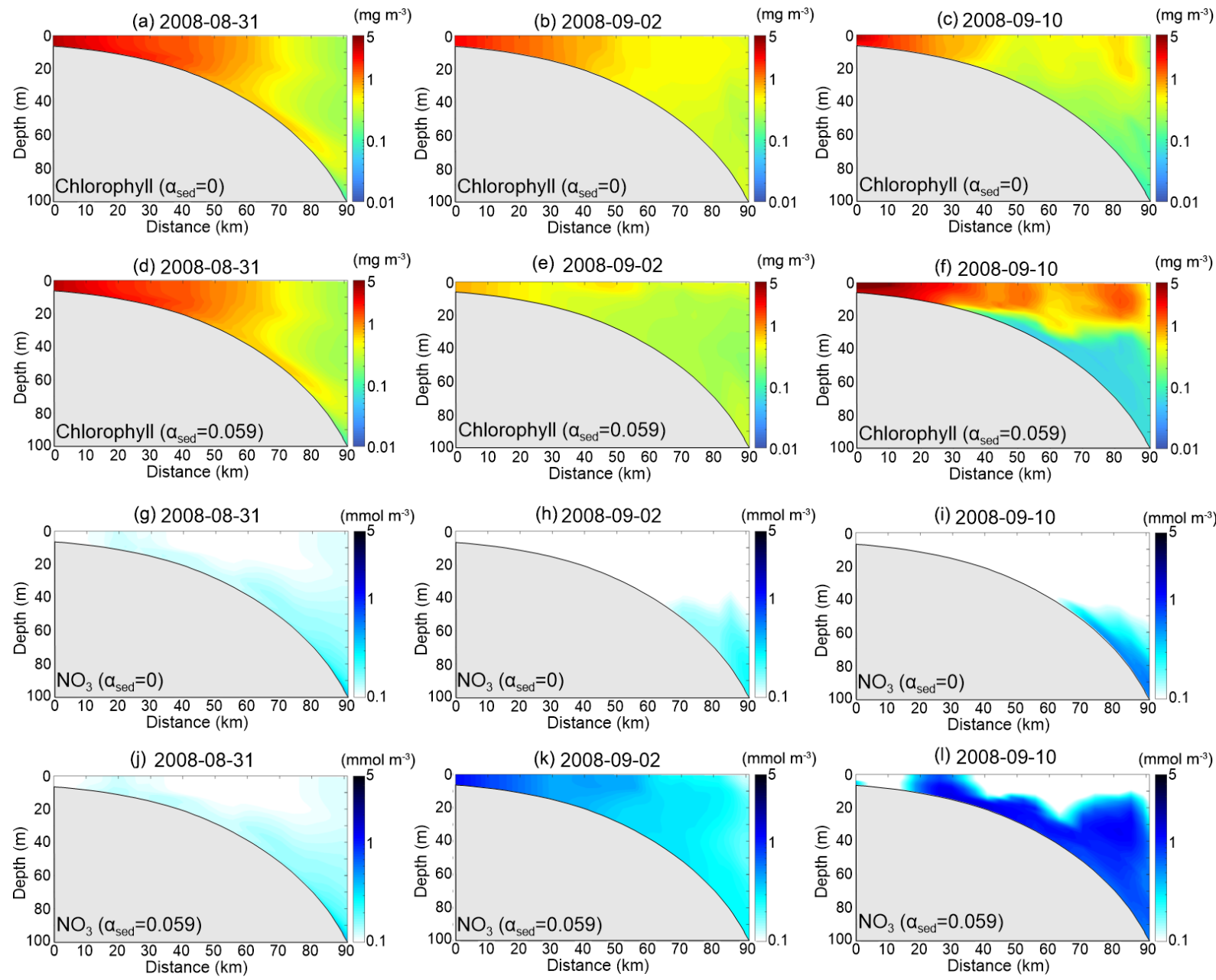

Figure 6. Model-simulated chlorophyll and $\mathrm{NO}_{3}$ along transect $\mathrm{D}$ on 31 August (first column), 2 September (second column) and 10 September (third column). (a-f) Chlorophyll concentration of the test 1 and benchmark run, respectively (note that the color scale is different from Fig. 3). (g-l) $\mathrm{NO}_{3}$ concentration of test 1 and benchmark run, respectively.
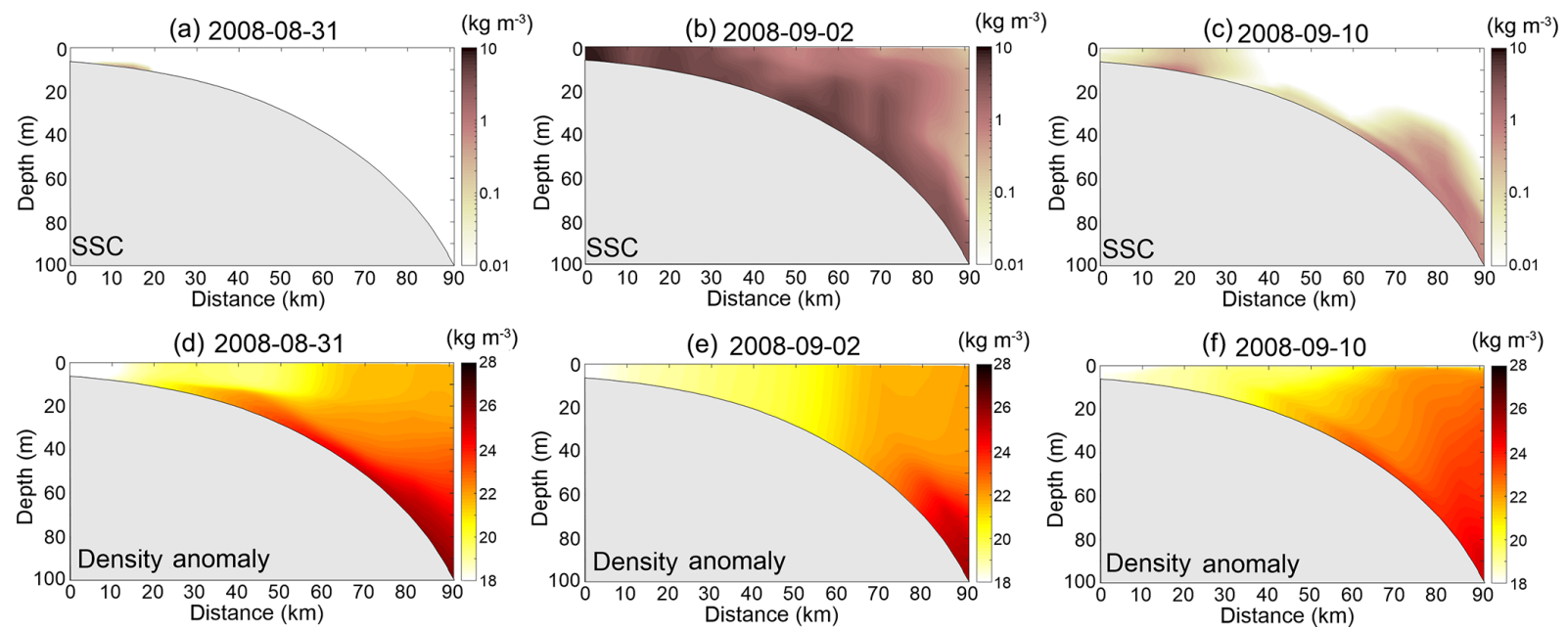

Figure 7. (a-c) Model-simulated suspended sediment concentration (SSC) and (d-f) water density anomaly along transect D on 31 August (a, d), 2 September $(\mathbf{b}, \mathbf{e})$ and 10 September $(\mathbf{c}, \mathbf{f})$, respectively. 


\subsection{The posthurricane offshore bloom}

Posthurricane blooms have been widely observed in the midand low-latitude oceans (Davis and Yan, 2004; Miller et al., 2006; Pan et al., 2017; D'Sa et al., 2019). A bloom in the open ocean was usually isolated and patchy, and its formation was mainly related to nutrients supplied from deep waters via vertical mixing (Pan et al., 2017; Walker et al., 2005). The mechanism of the bloom formation on the outer shelf, however, was more complex due to possible impacts from the inner shelf water. Strong post-Gustav cross-shelf transport has been reported by previous studies (Korobkin et al., 2009; Zang et al., 2018). The seaward dispersal of higher nutrient and chlorophyll coastal waters could have potentially contributed to the outer shelf bloom, but their respective contributions remained unclear. To quantify the cross-shore exported nutrient and chlorophyll, we estimated depth-integrated offshore (seaward) $\mathrm{NO}_{3}$ and chlorophyll flux along the $50 \mathrm{~m}$ isobath transect (Fig. 1b; Table 1). Compared with test $1\left(\mathrm{NO}_{3}-7.35 \mathrm{mmol} \mathrm{N}\left(\mathrm{ms} \mathrm{s}^{-1}\right)^{-1}\right.$; chlorophyll $\left.-66.88 \mathrm{mg}\left(\mathrm{m} \mathrm{s}^{-1}\right)^{-1}\right)$, the benchmark run estimated a higher $\mathrm{NO}_{3}$ flux $\left(38.71 \mathrm{mmol} \mathrm{N}\left(\mathrm{ms}^{-1}\right)^{-1}\right)$ and a lower chlorophyll flux $\left(43.10 \mathrm{mg}\left(\mathrm{ms}^{-1}\right)^{-1}\right)$. The differences in $\mathrm{NO}_{3}$ and chlorophyll fluxes between the two simulations could be explained by nutrient accumulation and NPP reduction on the inner shelf associated with resuspended sediment (Fig. 5a and c). Given the better offshore bloom intensity reproduced by the benchmark run (Fig. $3 \mathrm{~d}$ and e), we conclude that the posthurricane offshore bloom was mainly triggered by nutrients exported from the inner shelf water.

\subsection{Sensitivity to sediment light attenuation coefficient $\left(\alpha_{\text {sed }}\right)$}

A wide range of particle physical properties (e.g., size, shape, roughness and color) influence sediment light attenuation efficiency, which contributes to the difficulty in the parameterization of $\alpha_{\text {sed }}$ over a large region such as the nGoM (Baker and Lavelle, 1984; Storlazzi et al., 2015). To examine the sensitivity of primary production to sediment light attenuation efficiency, the results of sensitivity tests with different $\alpha_{\text {sed }}$ (tests 2-5) were compared against the benchmark run.

Ahead of Gustav's landfall, the difference in primary production between the benchmark run and sensitivity tests was limited (Fig. 8a), which suggested that the nGoM ecosystem was mainly limited by nutrients rather than light (Fennel et al., 2011). A total of $2 \mathrm{~d}$ after the landfall (1-3 September), high SSC suppressed photosynthesis in the entire water column, which overwhelmed the response associated with different $\alpha_{\text {sed }}$ settings. As such, primary production was not sensitive to $\alpha_{\text {sed }}$ from 1 to 3 September, although the nGoM ecosystem was also light limited. After 3 September, the differences in primary production and $\mathrm{NO}_{3}$ concentration increased among the sensitivity tests through 8 September (Fig. 8). Primary production became more sensitive to $\alpha_{\text {sed }}$ than SSC, which largely decreased due to settling (Fig. 5d). In the last $2 \mathrm{~d}$ of our simulation, the primary production differences reduced again to prehurricane conditions as the nGoM ecosystem shifted back to a nutrient-limited system.

In general, the influence of $\alpha_{\text {sed }}$ is significant when underwater light is limited by sediment and SSC was moderately high. The optical environment over the muddy inner Louisiana shelf is dominated by CDOM and chlorophyll under normal conditions (D'Sa and Miller, 2003). During energetic events (e.g., hurricanes and cold fronts), however, high concentrations of resuspended sediment become the most important light absorber. Given the high frequency of cold fronts in winter (once every 3-7 d) and energetic hurricanes in summer (Keim et al., 2007; Walker and Hammack, 2000), it is reasonable to speculate that the ecosystem along coastal Louisiana would be sensitive to $\alpha_{\text {sed }}$, not only on an event scale but also on seasonal to annual scales. The role of long-term sediment dynamics in water clarity and marine ecology has been reported in other regions (Capuzzo et al., 2015; Dupont and Aksnes, 2013; Wilson and Heath, 2019). To prove this hypothesis in the nGoM, we need a long-term biogeochemical simulation that explicitly includes sedimentinduced light attenuation effects in the future.

\subsection{Model uncertainties}

The optical environment over the muddy Louisiana shelf is dominated by phytoplankton, suspended sediment, CDOM and detritus particles (Le et al., 2014). The model presented in this study only includes the light attenuation due to the former two constituents, and the potential influence from CDOM and detritus warrants future study. Light attenuation due to CDOM was simply parameterized using salinity in a previous model study (Justić and Wang, 2014), yet few biogeochemical models incorporate dissolved and/or detritus-induced light attenuation. In the nGoM, CDOM plays an indispensable role in modulating the optical properties of inner shelf waters (D'Sa and Miller, 2003; D'Sa et al., 2018); thus, including CDOM-induced light attenuation would likely lower the threshold of sediment resuspension above which the nGoM ecosystem would be light limited. To estimate the importance of CDOM-induced light attenuation in the biogeochemical models, a long-term CDOM climatology is desired in the future.

We use SeaWiFS-derived chlorophyll concentrations to evaluate model performance. However, deriving high-quality chlorophyll data during hurricanes is still a challenge because (1) the presence of thick clouds limits the availability and quality of satellite images (Huang et al., 2011), (2) the uncertainty of chlorophyll estimation can be amplified by strong CDOM absorption (D'Sa et al., 2006; D'Sa and Miller, 2003), and (3) conducting chlorophyll measurements during a hurricane to calibrate bio-optical algorithms is limited by cost and safety. Given the rapid change in and a wide range of sediment and chlorophyll concentrations after 
Table 1. Offshore fluxes of $\mathrm{NO}_{3}$ and chlorophyll along the $50 \mathrm{~m}$ isobath transect (see location in Fig. 1b).

\begin{tabular}{|c|c|c|}
\hline Model runs & $\begin{array}{l}\text { Net offshore } \mathrm{NO}_{3} \text { flux } \\
\mathrm{mmol} \mathrm{N}\left(\mathrm{ms}^{-1}\right)^{-1}\end{array}$ & $\begin{array}{l}\text { Net offshore Chl flux } \\
\qquad\left(\mathrm{mg}\left(\mathrm{ms}^{-1}\right)^{-1}\right)\end{array}$ \\
\hline Benchmark run $\left(\alpha_{\text {sed }}=0.059\right)$ & 38.71 & 43.10 \\
\hline Test $1\left(\alpha_{\text {sed }}=0\right)$ & 7.35 & 66.88 \\
\hline
\end{tabular}

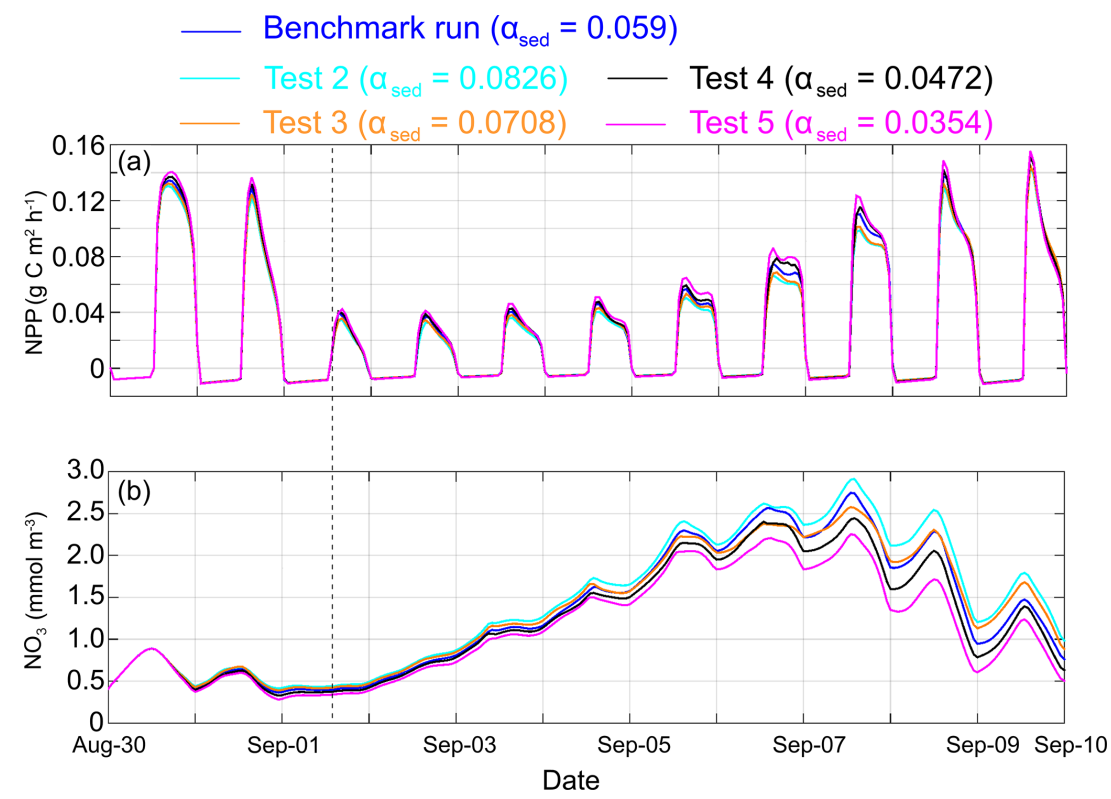

Figure 8. Comparison of spatially averaged (inner shelf; water depth $<50$ m) net primary production (a) and $\mathrm{NO}_{3}$ concentration (b) between benchmark run (blue) and sensitivity tests with different $\alpha_{\text {sed }}$. Note: test 2 - cyan; test 3 - orange; test 4 - black; and test 5 - magenta. The black dashed line shows the time of the Gustav landfall.

hurricanes, the algorithms based on observations under normal conditions might incur a bias. To achieve high-quality satellite-derived chlorophyll data, it is essential to optimize an algorithm based on field observations during hurricane events.

In this study we simplified $\alpha_{\text {sed }}$ as a constant over the entire GoM. When water is highly turbid, the availability of light for photosynthesis could be more related to sediment concentration rather than $\alpha_{\text {sed }}$ (McSweeney et al., 2017). Thus, using a constant to represent the sediment light attenuation coefficient when sediment concentration is high should not introduce considerable bias. The optical characteristics of sediment particles, however, could greatly modify light availability underwater when SSC is relatively low (Storlazzi et al., 2015). Our sensitivity tests also suggest the importance of $\alpha_{\text {sed }}$ in photosynthesis and primary production, as resuspended sediment settles back on the sea floor. Therefore, it is necessary to develop a spatially explicit $\alpha_{\text {sed }}$ to better parameterize the sediment's impact on light attenuation in future work.

Organic matter remineralization in sediment can dramatically increase nutrient concentration in the bottom boundary layer during strong resuspension (Couceiro et al., 2013).
Field measurements after hurricanes Gustav and Ike suggested that the resuspension can expose the organic material in sediment to a more favorable environment for respiration (McCarthy et al., 2013). Nevertheless, so far most biogeochemical models either neglect or simply parameterize this process (Chai et al., 2007; Fennel et al., 2006; Kishi et al., 2007). Moriarty et al. (2018) developed a particulate organic matter resuspension model and found that the remineralization intensity increased by an order of magnitude during moderate resuspension events in the nGoM. Given the strong storm-driven resuspension during hurricanes, nutrient dynamics can be modified greatly by remineralization after the storm passage as well. Thus, incorporating organic matter resuspension and remineralization, in conjunction with the light attenuation effects addressed in this study, will help to improve our understanding of a hurricane's impact on the biogeochemical cycling in shelf waters.

Our biogeochemical model includes freshwater and terrestrial nutrient input via a river channel. Du et al. (2019) estimated the freshwater budget during hurricane Harvey and found that surface runoff and groundwater accounted for $\sim 34 \%$ of the total freshwater load during the hurricane. Although our understanding of the nutrient flux associated with 
these two types of freshwater inputs is still limited, excluding surface runoff and groundwater flux in the model implies our underestimation of terrestrial nutrient discharge from the land. Coupling groundwater and hydrology models with an ocean model is a feasible way of achieving a comprehensive assessment of a hurricane's impact on the coastal and shelf ecosystem. In addition, water heating due to light absorption can also impact the ecosystem (Cahill et al., 2008; Mobley et al., 2015), but it has yet to be considered in our model.

\section{Conclusions}

We introduced a sediment-induced light attenuation algorithm to the ROMS biogeochemical model. The new model reproduced the biogeochemical cycling during Hurricane Gustav in the northern Gulf of Mexico. Improved model performance suggested that suspended sediment can play an important role in the underwater optical environment and primary production. During the passage of Gustav, the high SSC changed the inner shelf from a nutrient-limited environment to a light-limited one. NPP reduced from 0.05 to $0.01 \mathrm{~g} \mathrm{C}\left(\mathrm{m}^{2} \mathrm{~h}^{-1}\right)^{-1}$, then recovered to prehurricane conditions after 1 week of hurricane landfall. As the sediment further settled back on the seabed, nutrient accumulation and increased light availability incurred a strong surface posthurricane bloom on the inner shelf. A total of $9 \mathrm{~d}$ after Gustav's arrival, NPP below a $20 \mathrm{~m}$ water depth was still light limited due to the slow settling of sediment. The posthurricane bloom on the outer shelf was significantly enhanced by the laterally transported nutrients from the inner to the outer shelf. Suspended sediment affected primary production when SSC was moderately high after Gustav's landfall. For aquatic environments with great spatiotemporal variation in SSC (e.g., estuaries and lagoons), an optimal parameterization of sediment-induced light attenuation is imperative to better evaluate a hurricane's impact on coastal productivity and biogeochemical cycling.

Data availability. Data requests can be sent to the corresponding author via http://www.oceanography.lsu.edu/xuelab.

Supplement. The supplement related to this article is available online at: https://doi.org/10.5194/bg-17-5043-2020-supplement.

Author contributions. ZZ did the model setup, experiment design and data analysis and wrote the paper. ZGX supervised the project, was responsible for the funding acquisition and assisted with the review and editing of the paper, with input from KX, SJB, QC and EJD. SJB assisted with the conceptualization of the project, while $\mathrm{LZ}$ and $\mathrm{YO}$ were responsible for the model setup, data analysis and validation.
Competing interests. The authors declare that they have no conflict of interest.

Acknowledgements. We would like to thank the two anonymous reviewers for their comments. Computational support was provided by the High Performance Computing Cluster facility (SuperMike II) at Louisiana State University (LSU). Model results used in this study are archived on a data server maintained at the LSU Center for Computation and Technology.

Financial support. This research has been supported by the National Science Foundation (grant nos. CCF-1856359, EnvS1903340, OCE-1635837 and EAR-1427389), NASA (grant no. NNH17ZHA002C), the Louisiana Board of Regents (grant no. NASA/LEQSF(2018-20)-Phase3-11) and the LSU Foundation Billy and Ann Harrison Endowment for Sedimentary Geology.

Review statement. This paper was edited by Stefano Ciavatta and reviewed by two anonymous referees.

\section{References}

Allison, M. A., Demas, C. R., Ebersole, B. A., Kleiss, B. A., Little, C. D., Meselhe, E. A., Powell, N. J., Pratt, T. C., and Vosburg, B. M.: A water and sediment budget for the lower Mississippi-Atchafalaya River in flood years 20082010: Implications for sediment discharge to the oceans and coastal restoration in Louisiana, J. Hydrol., 432-433, 84-97, https://doi.org/10.1016/j.jhydrol.2012.02.020, 2012.

Arndt, S., Vanderborght, J., and Regnier, P.: Diatom growth response to physical forcing in a macrotidal estuary: Coupling hydrodynamics, sediment transport, and biogeochemistry, J. Geophys. Res.-Oceans, 112, C05045, https://doi.org/10.1029/2006JC003581, 2007.

Baker, E. T. and Lavelle, J. W.: Effect of Particle Size on the Light Attenuation Coefficient of Natural Suspensions, J. Geophys. Res., 89, 8197-8203, https://doi.org/10.1029/JC089iC05p08197, 1984.

Bianucci, L., Balaguru, K., Smith, R. W., Leung, L. R., and Moriarty, J. M.: Contribution of hurricane-induced sediment resuspension to coastal oxygen dynamics, Sci. Rep.-UK, 8, 15740, https://doi.org/10.1038/s41598-018-33640-3, 2018.

Bierman, V. J., Hinz, S. C., Zhu, D., Wiseman, W. J., Rabalais, N. N., and Turner, R. E.: A preliminary mass balance model of primary productivity and dissolved oxygen in the Mississippi River plume/inner Gulf Shelf region, Estuaries, 17, 886-899, 1994.

Booij, N., Ris, R. C., and Holthuijsen, L. H.: A third-generation wave model for coastal regions: 1 . Model description and validation, J. Geophys. Res.-Oceans, 104, 7649-7666, 1999.

Cahill, B., Schofield, O., Chant, R., Wilkin, J., Hunter, E., Glenn, S., and Bissett, P.: Dynamics of turbid buoyant plumes and the feedbacks on near-shore biogeochemistry and physics, Geophys. Res. Lett., 35, 1-6, https://doi.org/10.1029/2008GL033595, 2008.

Capuzzo, E., Stephens, D., Silva, T., Barry, J., and Forster, R. M.: Decrease in water clarity of the southern and central North Sea 
during the 20th century, Glob. Change Biol., 21, 2206-2214, https://doi.org/10.1111/gcb.12854, 2015.

Chai, F., Jiang, M. S., Chao, Y., Dugdale, R. C., Chavez, F., and Barber, R. T.: Modeling responses of diatom productivity and biogenic silica export to iron enrichment in the equatorial Pacific Ocean, Global Biogeochem. Cy., 21, 1-16, https://doi.org/10.1029/2006GB002804, 2007.

Cloern, J. E.: Turbidity as a control on phytoplankton biomass and productivity in estuaries, Cont. Shelf Res., 7, 1367-1381, 1987.

Couceiro, F., Fones, G. R., Thompson, C. E. L., Statham, P. J., Sivyer, D. B., Parker, R., Kelly-Gerreyn, B. A., and Amos, C. L.: Impact of resuspension of cohesive sediments at the Oyster Grounds (North Sea) on nutrient exchange across the sediment-water interface, Biogeochemistry, 113, 37-52, https://doi.org/10.1007/s10533-012-9710-7, 2013.

D'Sa, E. J. and Miller, R. L.: Bio-optical properties in waters influenced by the Mississippi River during low flow conditions, Remote Sens. Environ., 84, 538-549, https://doi.org/10.1016/S0034-4257(02)00163-3, 2003.

D'Sa, E. J., Miller, R. L., and Del Castillo, C.: Bio-optical properties and ocean color algorithms for coastal waters influenced by the Mississippi River during a cold front, Appl. Opt., 45, 7410-7428, 2006.

D'Sa, E. J., Korobkin, M., and Ko, D. S.: Effects of Hurricane Ike on the Louisiana-Texas coast from satellite and model data, Remote Sens. Lett., 2, 11-19, https://doi.org/10.1080/01431161.2010.489057, 2011.

D’Sa, E. J., Joshi, I., and Liu, B.: Galveston Bay and Coastal Ocean Optical-Geochemical Response to Hurricane Harvey From VIIRS Ocean Color, Geophys. Res. Lett., 45, 1057910589, doi:10.1029/2018GL079954, 2018.

Davis, A. and Yan, X. H.: Hurricane forcing on chlorophyll-a concentration off the northeast coast of the U.S., Geophys. Res. Lett., 31, 4-7, https://doi.org/10.1029/2004GL020668, 2004.

Devlin, M. J., Barry, J., Mills, D. K., Gowen, R. J., Foden, J., Sivyer, D., and Tett, P.: Relationships between suspended particulate material, light attenuation and Secchi depth in UK marine waters, Estuar. Coast. Shelf S., 79, 429-439, https://doi.org/10.1016/j.ecss.2008.04.024, 2008.

Du, J., Park, K., Dellapenna, T. M., and Clay, J. M.: Dramatic hydrodynamic and sedimentary responses in Galveston Bay and adjacent inner shelf to Hurricane Harvey, Sci. Total Environ., 653, 554-564, https://doi.org/10.1016/j.scitotenv.2018.10.403, 2019.

Dupont, N. and Aksnes, D. L.: Centennial changes in water clarity of the baltic sea and the north sea, Estuar. Coast. Shelf S., 131, 282-289, https://doi.org/10.1016/j.ecss.2013.08.010, 2013.

Fennel, K., Wilkin, J., Levin, J., Moisan, J., O’Reilly, J., and Haidvogel, D.: Nitrogen cycling in the Middle Atlantic Bight: Results from a three-dimensional model and implications for the North Atlantic nitrogen budget, Global Biogeochem. Cy., 20, $1-$ 14, https://doi.org/10.1029/2005GB002456, 2006.

Fennel, K., Wilkin, J., Previdi, M., and Najjar, R.: Denitrification effects on air-sea $\mathrm{CO}_{2}$ flux in the coastal ocean: Simulations for the northwest North Atlantic, Geophys. Res. Lett., 35, 1-5, https://doi.org/10.1029/2008GL036147, 2008.

Fennel, K., Hetland, R., Feng, Y., and DiMarco, S.: A coupled physical-biological model of the Northern Gulf of Mexico shelf: model description, validation and analysis of phytoplankton variability, Biogeosciences, 8, 1881-1899, https://doi.org/10.5194/bg-8-1881-2011, 2011.

Forbes, C., Luettich, R. A., Mattocks, C. A., and Westerink, J. J.: A Retrospective Evaluation of the Storm Surge Produced by Hurricane Gustav (2008): Forecast and Hindcast Results, Weather Forecast., 25, 1577-1602, https://doi.org/10.1175/2010WAF2222416.1, 2010.

Ganju, N. K., Miselis, J. L., and Aretxabaleta, A. L.: Physical and biogeochemical controls on light attenuation in a eutrophic, back-barrier estuary, Biogeosciences, 11, 7193-7205, https://doi.org/10.5194/bg-11-7193-2014, 2014.

Gomez, F. A., Lee, S.-K., Liu, Y., Hernandez Jr., F. J., MullerKarger, F. E., and Lamkin, J. T.: Seasonal patterns in phytoplankton biomass across the northern and deep Gulf of Mexico: a numerical model study, Biogeosciences, 15, 3561-3576, https://doi.org/10.5194/bg-15-3561-2018, 2018.

Haidvogel, D. B., Arango, H., Budgell, W. P., Cornuelle, B. D., Curchitser, E., Di Lorenzo, E., Fennel, K., Geyer, W. R., Hermann, A. J., Lanerolle, L., Levin, J., McWilliams, J. C., Miller, A. J., Moore, A. M., Powell, T. M., Shchepetkin, A. F., Sherwood, C. R., Signell, R. P., Warner, J. C., and Wilkin, J.: Ocean forecasting in terrain-following coordinates: Formulation and skill assessment of the Regional Ocean Modeling System, J. Comput. Phys., 227, 3595-3624, https://doi.org/10.1016/j.jcp.2007.06.016, 2008.

Huang, W., Mukherjee, D., and Chen, S.: Assessment of Hurricane Ivan impact on chlorophyll-a in Pensacola Bay by MODIS $250 \mathrm{~m}$ remote sensing, Mar. Pollut. Bull., 62, 490-498, https://doi.org/10.1016/j.marpolbul.2010.12.010, 2011.

Hurst, N. R., White, J. R., Xu, K., and Ren, M.: Nitrate reduction rates in sediments experiencing turbulent flow conditions, Ecol. Eng., 128, 33-38, https://doi.org/10.1016/j.ecoleng.2018.12.027, 2019.

Jacob, R., Larson, J., and Everest, O.: $\mathrm{M} \times \mathrm{N}$ Communication and Parallel Interpolation in Community Climate System Model Version 3 Using the Model Coupling Toolkit, Int. J. High Perform. C., 19, 293-307, https://doi.org/10.1177/1094342005056116, 2005.

Justić, D. and Wang, L.: Assessing temporal and spatial variability of hypoxia over the inner Louisiana-upper Texas shelf: Application of an unstructured-grid three-dimensional coupled hydrodynamic-water quality model, Cont. Shelf Res., 72, 163179, https://doi.org/10.1016/j.csr.2013.08.006, 2014.

Keim, B. D., Muller, R. A., and Stone, G. W.: Spatiotemporal patterns and return periods of tropical storm and hurricane strikes from Texas to Maine, J. Climate, 20, 3498-3509, https://doi.org/10.1175/JCLI4187.1, 2007.

Kishi, M. J., Kashiwai, M., Ware, D. M., Megrey, B. A., Eslinger, D. L., Werner, F. E., Noguchi-Aita, M., Azumaya, T., Fujii, M., and Hashimoto, S.: NEMURO - a lower trophic level model for the North Pacific marine ecosystem, Ecol. Modell., 202, 12-25, 2007.

Korobkin, M., D'Sa, E., and Ko, D. S.: Satellite observations and NCOM assessment of the Mississippi-Louisiana-Texas coast following hurricanes Gustav and Ike, OCEANS 2009, Biloxi, MS, 1-4, https://doi.org/10.23919/OCEANS.2009.5422213, 2009.

Laurent, A. and Fennel, K.: Simulated reduction of hypoxia in the northern Gulf of Mexico due to phosphorus limitation, Elementa, 
2, 1-12, https://doi.org/10.12952/journal.elementa.000022, 2014.

Laurent, A., Fennel, K., Hu, J., and Hetland, R.: Simulating the effects of phosphorus limitation in the Mississippi and Atchafalaya River plumes, Biogeosciences, 9, 4707-4723, https://doi.org/10.5194/bg-9-4707-2012, 2012.

Le, C., Lehrter, J. C., Hu, C., Murrell, M. C., and Qi, L.: Spatiotemporal chlorophyll-a dynamics on the Louisiana continental shelf derived from a dual satellite imagery algorithm, J. Geophys. Res.-Oceans, 119, 7449-7462, 2014.

Lin, S., Zou, T., Gao, H., and Guo, X.: The vertical attenuation of irradiance as a function of turbidity: a case of the Huanghai (Yellow) Sea in spring, Acta Oceanol. Sin., 28, 66-75, 2009.

Liu, K., Chen, Q., Hu, K., Xu, K., and Twilley, R. R.: Modeling hurricane-induced wetland-bay and bay-shelf sediment fluxes, Coast. Eng., 135, 77-90, https://doi.org/10.1016/j.coastaleng.2017.12.014, 2018.

McCarthy, M. J., Carini, S. A., Liu, Z., Ostrom, N. E., and Gardner, W. S.: Oxygen consumption in the water column and sediments of the northern Gulf of Mexico hypoxic zone, Estuar. Coast. Shelf S., 123, 46-53, https://doi.org/10.1016/j.ecss.2013.02.019, 2013.

McSweeney, J. M., Chant, R. J., Wilkin, J. L., and Sommerfield, C. K.: Suspended-Sediment Impacts on Light-Limited Productivity in the Delaware Estuary, Estuar. Coast., 40, 977-993, https://doi.org/10.1007/s12237-016-0200-3, 2017.

Meade, R. H. and Moody, J. A.: Causes for the decline of suspended-sediment discharge in the Mississippi River system, 1940-2007, Hydrol. Process., 24, 35-49, 2010.

Miller, W. D., Harding, L. W., and Adolf, J. E.: Hurricane Isabel generated an unusual fall bloom in Chesapeake Bay, Geophys. Res. Lett., 33, 2-5, https://doi.org/10.1029/2005GL025658, 2006.

Mobley, C. D., Chai, F., Xiu, P., and Sundman, L. K.: Impact of improved light calculations on predicted phytoplankton growth and heating in an idealized upwelling-downwelling channel geometry, J. Geophys. Res.-Oceans, 120, 875-892, 2015.

Moriarty, J. M., Harris, C. K., Friedrichs, M. A. M., Fennel, K., and $\mathrm{Xu}, \mathrm{K}$. : Impact of seabed resuspension on oxygen and nitrogen dynamics in the northern Gulf of Mexico: A numerical modeling study, J. Geophys. Res.-Oceans, 123, 7237-7263, https://doi.org/10.1029/2018JC013950, 2018.

Pan, G., Chai, F., Tang, D. L., and Wang, D.: Marine phytoplankton biomass responses to typhoon events in the South China Sea based on physical-biogeochemical model, Ecol. Modell., 356, 38-47, https://doi.org/10.1016/j.ecolmodel.2017.04.013, 2017.

Pennock, J. R.: Chlorophyll distributions in the Delaware estuary: regulation by light-limitation, Estuar. Coast. Shelf S., 21, 711$725,1985$.

Rabalais, N. N., Turner, R. E., and Wiseman, W. J.: Hypoxia in the Gulf of Mexico, J. Environ. Qual., 30, 320-329, 2001.

Saha, S., Moorthi, S., Pan, H. L., Wu, X., Wang, J., Nadiga, S., Tripp, P., Kistler, R., Woollen, J., and Behringer, D.: NCEP climate forecast system reanalysis (CFSR) 6-hourly products, January 1979 to December 2010, Res. Data Arch., Natl. Cent. Atmos. Res., Comput. Inf. Syst. Lab., Boulder, CO, 2010.

Saha, S., Moorthi, S., Wu, X., Wang, J., Nadiga, S., Tripp, P., Behringer, D., Hou, Y. T., Chuang, H., and Iredell, M.: NCEP climate forecast system version 2 (CFSv2) 6-hourly products, Res.
Data Arch., Natl. Cent. Atmos. Res., Comput. Inf. Syst. Lab., 2011.

Schaeffer, B. A., Sinclair, G. A., Lehrter, J. C., Murrell, M. C., Kurtz, J. C., Gould, R. W., and Yates, D. F.: An analysis of diffuse light attenuation in the northern Gulf of Mexico hypoxic zone using the SeaWiFS satellite data record, Remote Sens. Environ., 115, 3748-3757, https://doi.org/10.1016/j.rse.2011.09.013, 2011.

Shchepetkin, A. F. and McWilliams, J. C.: The regional oceanic modeling system (ROMS): A split-explicit, free-surface, topography-following-coordinate oceanic model, Ocean Model., 9, 347-404, https://doi.org/10.1016/j.ocemod.2004.08.002, 2005.

Skamarock, W. C., Klemp, J. B., Dudhia, J., Gill, D. O., Barker, D. M., Duda, M. G., Huang, X.-Y., Wang, W., and Powers, J. G.: A description of the Advanced Research WRF version 3, in NCAR Tech. Note NCAR/TN-475+ STR, Natl. Cent. for Atmos. Res, Boulder, Colo., 2008.

Storlazzi, C. D., Norris, B. K., and Rosenberger, K. J.: The influence of grain size, grain color, and suspended-sediment concentration on light attenuation: Why fine-grained terrestrial sediment is bad for coral reef ecosystems, Coral Reefs, 34, 967-975, https://doi.org/10.1007/s00338-015-1268-0, 2015.

Thewes, D., Stanev, E. V., and Zielinski, O.: Sensitivity of a 3D Shelf Sea Ecosystem Model to Parameterizations of the Underwater Light Field, Front. Mar. Sci., 6, 816, https://doi.org/10.3389/fmars.2019.00816, 2020.

Van Duin, E. H. S., Blom, G., Los, F. J., Maffione, R., Zimmerman, R., Cerco, C. F., Dortch, M., and Best, E. P. H.: Modeling underwater light climate in relation to sedimentation, resuspension, water quality and autotrophic growth, Hydrobiologia, 444, 25-42, 2001.

Walker, N. D. and Hammack, A. B.: Impacts of winter storms on circulation and sediment transport: Atchafalaya-Vermilion Bay region, Louisiana, USA, J. Coast. Res., 16, 996-1010, 2000.

Walker, N. D., Leben, R. R., and Balasubramanian, S.: Hurricaneforced upwelling and chlorophyll a enhancement within coldcore cyclones in the Gulf of Mexico, Geophys. Res. Lett., 32, 1-5, https://doi.org/10.1029/2005GL023716, 2005.

Warner, J. C., Sherwood, C. R., Signell, R. P., Harris, C. K., and Arango, H. G.: Development of a threedimensional, regional, coupled wave, current, and sedimenttransport model, Comput. Geosci., 34, 1284-1306, https://doi.org/10.1016/j.cageo.2008.02.012, 2008.

Warner, J. C., Armstrong, B., He, R., and Zambon, J. B.: Development of a Coupled Ocean-Atmosphere-Wave-Sediment Transport (COAWST) Modeling System, Ocean Model., 35, 230-244, https://doi.org/10.1016/j.ocemod.2010.07.010, 2010.

Wilson, R. F., Fennel, K., and Paul Mattern, J.: Simulating sediment-water exchange of nutrients and oxygen: A comparative assessment of models against mesocosm observations, Cont. Shelf Res., 63, 69-84, https://doi.org/10.1016/j.csr.2013.05.003, 2013.

Wilson, R. J. and Heath, M. R.: Increasing turbidity in the North Sea during the 20th century due to changing wave climate, Ocean Sci., 15, 1615-1625, https://doi.org/10.5194/os-15-1615-2019, 2019. 
Wiseman, W. J., Rabalais, N. N., Turner, R. E., Dinnel, S. P., and MacNaughton, A.: Seasonal and interannual variability within the Louisiana coastal current: stratification and hypoxia, J. Mar. Syst., 12, 237-248, 1997.

Xu, K., Harris, C. K., Hetland, R. D., and Kaihatu, J. M.: Dispersal of Mississippi and Atchafalaya sediment on the Texas-Louisiana shelf: Model estimates for the year 1993, Cont. Shelf Res., 31, 1558-1575, https://doi.org/10.1016/j.csr.2011.05.008, 2011.

Xu, K., Mickey, R. C., Chen, Q., Harris, C. K., Hetland, R. D., Hu, K., and Wang, J.: Shelf sediment transport during hurricanes Katrina and Rita, Comput. Geosci., 90, 24-39, https://doi.org/10.1016/j.cageo.2015.10.009, 2016.

Xue, Z., He, R., Fennel, K., Cai, W.-J., Lohrenz, S., and Hopkinson, C.: Modeling ocean circulation and biogeochemical variability in the Gulf of Mexico, Biogeosciences, 10, 7219-7234, https://doi.org/10.5194/bg-10-7219-2013, 2013.

Yu, L., Fennel, K., and Laurent, A.: A modeling study of physical controls on hypoxia generationin the northern Gulf of Mexico, J. Geophys. Res.-Oceans, 120, 5019-5039, https://doi.org/10.1002/2014JC010634, 2015.
Zang, Z., Xue, Z. G., Bao, S., Chen, Q., Walker, N. D., Haag, A. S., Ge, Q., and Yao, Z.: Numerical study of sediment dynamics during hurricane Gustav, Ocean Model., 126, 29-42, https://doi.org/10.1016/j.ocemod.2018.04.002, 2018.

Zang, Z., Xue, Z. G., Xu, K., Bentley, S. J., Chen, Q., D’Sa, E. J., and Ge, Q.: A Two Decadal (1993-2012) Numerical Assessment of Sediment Dynamics in the Northern Gulf of Mexico, Water, 11, 938, https://doi.org/10.3390/w11050938, 2019.

Zhao, Y. and Quigg, A.: Nutrient limitation in Northern Gulf of Mexico (NGOM): Phytoplankton communities and photosynthesis respond to nutrient pulse, PLoS One, 9, e88732, https://doi.org/10.1371/journal.pone.0088732, 2014.

Zhou, F., Chai, F., Huang, D., Xue, H., Chen, J., Xiu, P., Xuan, J., Li, J., Zeng, D., Ni, X., and Wang, K.: Investigation of hypoxia off the Changjiang Estuary using a coupled model of ROMS-CoSiNE, Prog. Oceanogr., 159, 237-254, https://doi.org/10.1016/j.pocean.2017.10.008, 2017.

Zhu, Z., Ng, W., Liu, S., Zhang, J., Chen, J., and Wu, Y.: Estuarine phytoplankton dynamics and shift of limiting factors: A study in the Changjiang (Yangtze River) Estuary and adjacent area, Estuar. Coast. Shelf S., 84, 393-401, 2009. 